\title{
LAS ÚLTIMAS PALABRAS DE VIDELA Y MELI EN TRIBUNALES ARGENTINOS. EMERGENCIAS Y ARTICULACIÓN DE OBJETOS DE DISCURSO
}

\author{
PAULO DAMIÁN ANICETO ${ }^{1}$ \\ Centro de Investigaciones de la Facultad de Filosofía y Humanidades \\ Universidad Nacional de Córdoba, CONICET, Córdoba, Argentina \\ paulodamiananiceto@gmail.com
}

\begin{abstract}
Resumen. En este artículo, ofrecemos los resultados del análisis semiótico de las últimas palabras de dos acusados por crímenes de lesa humanidad, Jorge R. Videla y Vicente Meli en Tribunales de Justicia argentinos. Desde una perspectiva anclada en la teoría jurídica crítica que asume el campo judicial como un ámbito polémico, reconocemos la construcción de singulares enunciadores y objetos de discurso por parte de distintos actores procesales. Ambos acusados dan a la emergencia de enunciadores que dramatizan argumentos jurídicos desde una posición profesional, invirtiendo la posición lega atribuida por la lex scripta, la querella, los magistrados y hasta la defensa. Palabras clave: últimas palabras; delitos de lesa humanidad; semiótica jurídica.
\end{abstract}

\begin{abstract}
In this paper we offer results of a semiotic analysis on final words of two accused of crimes against humanity, Jorge R. Videla and Vicente Meli. We recognize singular utters and objects of discourse to be built by differents procedural actors. We recognize it from a semiotic perspective anchored in the Critical Legal Studies wich assume the judicial field as a polemic ambit or sphere. Both defendants strategically dramatize legal arguments from a professional position, in opposition to legal-lay position that prosecution, the judges, as well as defense, attribute to them.
\end{abstract}

Keywords: judicial last words; crimes against humanity; legal semiotics.

\section{Introducción}

La inclusión de la figura penal crímenes de lesa humanidad al ordenamiento jurídico argentino presenta características diferenciales que se explican por dos variables históricas. La primera está relacionada con la singular y compleja reconfiguración política que siguió al final del gobierno militar de facto de este país, a finales de 1983. El nuevo gobierno democrático de Raúl Alfonsín debía garantizar tanto la traducción judicial de la condena popular que para ese entonces pesaba sobre la formación castrense como la subordinación definitiva de las Fuerzas Armadas al orden constitucional. Se encontraba

\footnotetext{
${ }^{1}$ Licenciado en Comunicación Social y Doctorando de la Universidad Nacional de Córdoba - mención Semiótica.
} 
frente al reclamo de la sociedad argentina y bajo la presión de la formación castrense, ante la disyuntiva entre construir una transición pactada o una de ruptura (SIKKINK, 2013). La segunda variable deviene de la ratificación argentina a la Convención sobre la Imprescriptibilidad de los Crímenes de Guerra y de los Crímenes de Lesa Humanidad, producida en 2003 (FEIERSTEIN, 2015).

Por esto, las investigaciones académicas latinoamericanas (especialmente brasileras y argentinas) que analizan el discurso de los acusados por crímenes de lesa humanidad lo hacen con el foco en materiales recogidos en un proceso singular: el de rituales de enjuiciamiento estatal que otorgan la palabra a acusados de cometer un crimen en nombre del Estado.

En este artículo, analizamos las estrategias discursivas desplegadas por dos acusados de crímenes de lesa humanidad en tribunales argentinos, durante sus últimas palabras. Éste pretende ser un aporte a la tradición analítica de la Semiótica Jurídica (SJ), que asume la tarea de describir la relación significante entre narración, derecho y acontecimiento en los ritos judiciales.

Concebimos el campo discursivo judicial (MARÍ, 1982 [1980]; LANDOWSKI, 1990 [1986]; FOUCAULT, 2014 [2012]) como un dominio compuesto por enunciados con pretensión de corrección jurídica (ALEXY, 2011 [1978]), que interpelan a otros enunciados a dotarse de la justificación interna que ellos se atribuyen. Los ritos judiciales por crímenes de lesa humanidad realizados en Argentina componen, en este sentido, escenas de relatos contrapuestos que disputan el sentido del pasado nacional reciente. Como sostiene Robert Alexy (2011 [1978]), por medio de argumentos históricos, los sujetos procesales dramatizan argumentos jurídicos. La narración de los hechos construye la ilusión referencial (BARTHES, 2013 [1968]) que establece una correspondencia entre el objeto procesal y los hechos pasados. pero, sin embargo, más que constatar, performan (DERRIDA, 1992) y más que referir, instituyen (LANDOWSKI et al., 1980 [1976]).

El afluente argentino de lo que Kathryn Sikkink (2013) denomina cascada de justicia $^{2}$ tiene la virtud de haber orientado la posibilidad de juzgar crímenes de funcionarios públicos con aquiescencia del Estado. Los 16 años transcurridos desde la sanción y reglamentación de las leyes de Obediencia Debida y Punto Final hasta la adhesión legislativa a la Convención sobre la imprescriptibilidad de los Crímenes de Guerra y de los Crímenes de Lesa Humanidad, en agosto de 2003, configuran especiales condiciones de emergencia de relatos judiciales divergentes del pasado.

Desde la reapertura de las causas por parte de la Corte Suprema de Justicia argentina, en 2005, el Ministerio Público Fiscal reabrió decenas de investigaciones pendientes e impulsó otras. En el marco de estos procesos es que es llevado a cabo el juicio en el Tribunal Oral Federal 1 de la ciudad de Córdoba, que comenzó el viernes 2 de julio de 2010 y, seis meses después, constituyó la escena de las últimas palabras de Rafael Videla y Vicente Meli. La sentencia que los jueces dictarían sería la trigésima novena de este período, en un proceso donde 25 imputados, el número más grande hasta

\footnotetext{
${ }^{2}$ En La cascada de la justicia, la autora ofrece una narración de los procesos judiciales tramitados en tribunales de Grecia, en 1975, y Portugal, en 1976. Ambos juzgaron crímenes categorizados abiertamente como Terrorismo de Estado y son considerados por Sikkink (2013) como los primeros afluentes de la tercera ola democratizadora.
} 
aquel momento, enfrentaron acusaciones por dos causas UP1 (Unión Penintenciaria $n^{\circ}$ 1) y Gontero.

Este establecimiento carcelario fue, durante la dictadura cívico-militar argentina (1976-1983), uno de los destinos de aquellos que, luego de transitar centros clandestinos de detención, eran finalmente blanqueados, como se denominaba el acto de oficializar la detención y puesto a disposición directa del Poder Ejecutivo Nacional de facto.

Con el golpe militar del 24 de marzo de 1976, el máximo cargo ejecutivo fue tomado por Videla, que para aquel momento era Presidente de la Junta Militar y Comandante General del Ejército. Meli, por su parte, era un Coronel del Ejército que se desempeñaba en el Comando de Brigada de Infantería Aerotransportada IV de Córdoba como Jefe de Estado Mayor desde el 21 de junio de 1976. Ambos fueron acusados por imposición de tormentos agravados por su condición de funcionarios públicos, homicidio calificado, y encubrimiento en perjuicio de la totalidad de las víctimas comprobadas en la causa.

El alegato del fiscal Maximiliano Hairabedián, luego de argumentar que las audiencias habían probado el sistemático plan represivo como un plan de eliminación de opositores, aseguró que

[...] en la cárcel penitenciaria, hubo un antes y un después, narrado por todos los ex detenidos que declararon en esta causa. Hubo un régimen antes y otro después del 24 de marzo. Antes no los sacaron para matarlos y después sí [...]. Ya estaban lanzados en este plan de exterminio y no lo detuvieron. Programa que ideológicamente se lo he atribuido a él [Videla] incluso desde sus albores (la aclaración es mía).

\section{Marco teórico}

Para este estudio, adoptamos la definición de discurso acuñada por Foucault (2008 [1971], 2011 [1969]). El autor concibe el discurso como una práctica ritual que emerge en contextos condicionados histórica e institucionalmente y es controlada o excluida y separada en determinados dominios de verdad. Esta práctica está ligada constitutivamente con su dimensión performativa o realizadora. Es decir, la gramática normativa, la normatividad, constriñe la forma de la práctica judicial pero no consigue dominar las derivas de su ocurrencia en el campo discursivo procesal. Desde una perspectiva deconstructivista, asumimos la performatividad de la práctica discursiva, antes que como el carácter variante de algunos enunciados que hacen cosas con palabras, como la designación de lo que ocurre cuando un acto de enunciación emerge en campos discursivos agonísticos. Es decir, consideramos, como lo hacen Derridá (1992), Butler (2003), Ruiz (2009), Cárcova (2009) y García Romanutti (2014), que un enunciado judicial hace ocurrir o produce simbólicamente un acontecimiento que no es registrado por la ciencia jurídica. Irrumpe como una remisión al pasado del dogma jurídico, como una referencia que accede sin mediación a lo referido. Sin embargo, no deja de ser lo que aparece en el presente, un acontecimiento raro (Foucault, 2008 [1971]) que produce la diferencia y el trastoque del pasado al mismo tiempo que se presenta como comentario, como su repetición subsidiaria. 
Los juegos estratégicos y polémicos de las últimas palabras de Videla y Meli son desplegados, en este sentido, mediante estrategias que inscriben singulares dominios de memoria. Es decir, se integran al juego más amplio de la verdad jurídica, con la apariencia tanto de necesidad jurídica (KENNEDY, 2010) como de fidelidad histórica. La práctica discursiva judicial, en todo su espesor y su contingencia, es construida bajo el ejido de los enunciados normativos al tiempo que lo desbordan.

Desde este punto de vista, cobra relevancia el trabajo de reconocer, en el campo en el que funciona la práctica judicial, el funcionamiento de un singular dispositivo de saber. Su principal característica está dada en la tensión estratégica entre los actores autorizados a decir el derecho y practicar el saber dogmático y los actores legos cuyas palabras aparecen como las del autor de la ley que dicta los procedimientos (FOUCAULT, 2014 [2012]).

Los dos enunciados que componen nuestro corpus son atribuidos aquí a sujetos legos que despliegan una estrategia de inversión de esa tensión y, por lo tanto, componen una superficie de emergencia de referentes u objetos de discurso (MONDADA; DUBOIS, 2003 [1995]).

Entendemos la operación formal de adjudicación de normas a hechos, no como una remisión a un referente previo, sino como la construcción estratégica de una referencia de justicia o, en palabras de Alena Ciulla e Silva et al. (2008), como acto de referenciación.

Emprendemos este análisis con la mirada en los mecanismos de construcción discursiva de referentes o ámbitos de justicia, como los denomina Foucault (2014 [2012]). La selección de los dos primeros discursos del espacio de las últimas palabras del juicio en tribunales orales de Córdoba, Argentina, de Jorge R. Videla y Vicente Meli, reviste precisamente este interés. Ambos construyen una singular relación entre un sí mismo profesional castrense vigente y un sí mismo profesional jurídico que se auto-asignan como una relación justa. Esto puede reconocerse en un fragmento del enunciado de Vicente Meli: "[...] adhiero totalmente a lo expresado por el Teniente General Jorge Rafael Videla. Menciono su grado y cargo, porque para mí, educado en el ejército, continuará siendo mi comandante en jefe $[\ldots] "$.

Cobran relevancia dos preguntas significativas para nuestro trabajo: ¿qué verdad es construida por un relato que no está obligado por la autoridad del rito ni será incluido a la verdad diferida de la sentencia? ¿Es el relato del Juez con efectos jurídico-penales la única instancia de ajuste narrativo?

Los registros sonoros y las desgrabaciones de las últimas palabras han sido puestos a disposición por el Archivo de la Memoria de Córdoba, con autorización de cesión del Tribunal Oral Federal $n^{\circ}$ 1, dependiente del Poder Judicial de la Nación. Sin embargo, en consonancia con una acordada de prensa elaborada por la institución oficial, mientras las causas "Gontero y UP1" no cuenten con sentencia firme ${ }^{4}$, se encuentra restringida la publicación de la versión gráfica completa de los testimonios ${ }^{5}$.

\footnotetext{
${ }^{4}$ A la fecha de elaboración de este artículo continúa en la misma situación.

${ }^{5}$ Sin embargo, la versión sonora se encuentra disponible en archivos digitales alojados en las siguientes URLs: $\quad$ http://www.eldiariodeljuicio.com.ar/?q=multimedia-audio/2\%2B19/518; http://www.eldiariodeljuicio.com.ar/?q=multimedia-audio/2\%2B19/519
} 


\section{Resultados}

Durante la última audiencia del juicio oral y público conocido como $U P 1$, los acusados Jorge Rafael Videla y Vicente Meli, ex militares argentinos, tomaron una opción prevista por la ley Procesal argentina: pronunciar unas últimas palabras. Ambos fueron acusados por el Ministerio Público Fiscal como responsables de las torturas y homicidios que componen la causa que, junto a la denominada Gontero, compone el juicio. La UP1 funcionó como un centro para la detención de presos políticos a disposición directa del poder ejecutivo de facto. Los presos políticos compartían, por entonces, el edificio de la cárcel con condenados por delitos comunes.

De los 31 acusados en el juicio, 17 eran ex militares. Entre las mañanas del 21 y 22 de diciembre de 2010, 13 de los 31 acusados accedieron a la instancia de las últimas palabras, de los cuales cinco eran ex militares. Los primeros dos, convocados en voz alta por el juez Jaime Diaz Gavier, enunciaron sus últimas palabras referenciando un colectivo profesional militar que aporta a un destinatario dos pruebas de su vigencia y su juridicidad. En una aproximación lingüística, que aquí no profundizaremos, sería posible reconocer la primera de esas pruebas, plasmada en marcas lingüísticas (deícticos de persona -nosotros-, elementos referenciales -las Fuerzas Armadas de la Patria- y sintagmas nominales). Éstas remiten a una estrategia auto-referencial que, por un lado, repone un singular referente de justicia y lo representa como natural de una formación militar y, por otro lado, incluye al enunciador construido en dicha formación.

El análisis al que dedicamos este artículo expone una descripción de las estrategias desplegadas por los acusados para construir la segunda de esas pruebas. Ésta es eminentemente argumentativa y aparece en la polifonía judicial superponiendo, a los límites formales del rito, los simbólicos del argumento histórico. El discurso de las últimas palabras crea una tensión estratégica entre un objeto procesal polémico, sin un reconocimiento formal, y el delimitado por posicionamientos autoritativos. Este análisis parte de un presupuesto: aquellos que toman la palabra desde el banquillo lo hacen construyendo enunciadores que dramatizan sujetos que invierten la carga de la argumentación.

\subsection{Objetos de discurso construidos}

Los objetos de discurso reconocidos en el análisis, entre los que se encuentra el objeto procesal polémico, traban una disputa simbólica con los construidos en los enunciados del fiscal, como vimos. En una estrategia de auto-justificación, los enunciados de Videla y Meli argumentan su adecuación formal al rito y se presentan como sujetos de objeciones profesionales, como peritos jurídicos que minan, desde sus pliegues, el proceso al que se habían adecuado.

Es decir, oponen una objeción a la gramática que rotula sus enunciados como palabras de acusados. 


\subsubsection{El objeto procesal alternativo: estado de guerra}

Uno de los objetos de discurso delimitados en los enunciados de Videla y Meli es el representado polémicamente como un objeto procesal alternativo construido en un paradigma de designaciones que incluye, por ejemplo, la fórmula posiciones en guerra.

Jorge Rafael Videla (V): Señores jueces, mucho se ha dicho y se ha escrito sobre lo ocurrido en nuestra patria durante los años de la década del setenta. Con una visión lamentablemente sesgada de la realidad no exenta de dudoso propósito, ocultando parte de los años tremendos de esa guerra.

Vicente Meli (M): El sentido común y la experiencia acreditan que no se puede investigar hechos acontecidos hace treinta y cinco años prescindiendo de un completo análisis histórico, socio político e institucional, que no hubiera recurrido a suposiciones y conjeturas para acusar e imputar en tiempos de paz a acciones ocurridas en tiempos de guerra. [...] Según palabras que constan en la causa 13/84, no hubo delincuentes políticos, sino enemigos de guerra bélicamente iguales.

En torno a ese objeto polémico, es inscrito un dominio de memoria que atribuye diferentes funciones a diferentes actores y define sus roles en la historia narrada en relación con un mismo acontecimiento: la guerra.

Las últimas palabras de Videla y Meli referencian la interpretación 'justa' del pasado como aquella que condiciona la validez del objeto procesal al reconocimiento de dos instancias: 1- el pasado juzgado como un escenario de contienda en el que un actor defiende el orden institucional de la pretensión de su contrincante y 2- el juicio como la continuidad, en el presente, del pasado de esa contienda.

En este marco, la categoría terrorista y las que la sobre-especifican reenvían al mismo objeto. El pasado estado de guerra es denominado por el relato como una instancia durante la cual el enunciador de las últimas palabras desempeñó funciones jurídicas estatales. En el dominio referencial donde se inscriben los enunciados emergentes, entonces, podemos reconocer que la narración de ese pasado instaura una gramática jurídica que podemos esbozar: el ejercicio la profesión militar (que es re-compuesta simbólicamente en los discursos) solventa el ejercicio de la práctica estatal con fundamento jurídico.

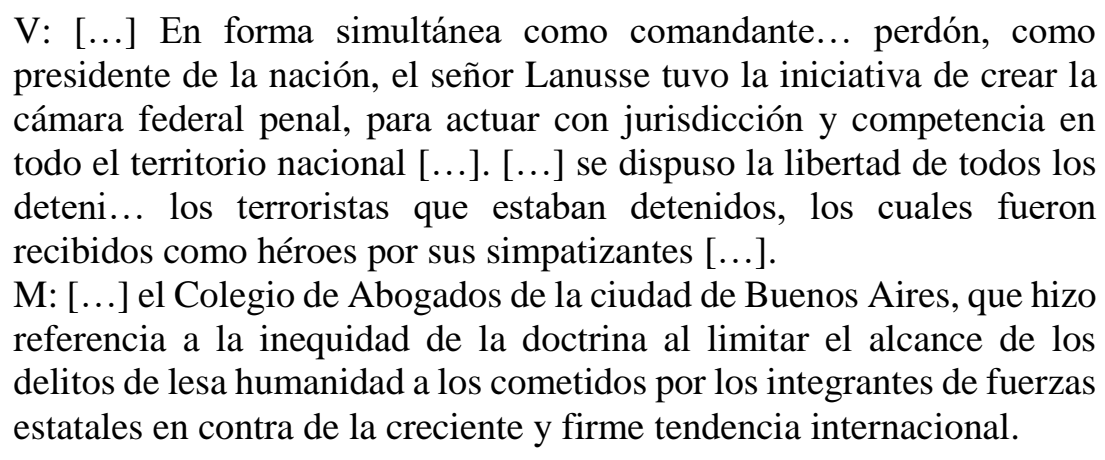

Así, en el marco de la guerra, uno de los contrincantes es representado como un actor ubicado fuera de los límites del sistema legal. No es categorizado por su aprehensión 
o encarcelamiento (detenidos) sino por su condición relativa al estado de guerra (terroristas que estaban detenidos).

En el otro extremo, los rasgos atribuidos a los actores con investidura institucional (Lanusse, Fuerzas Estatales), operan como refuerzo del argumento histórico-jurídico. Tanto las categorías asignadas a estos actores como las asignadas a la contraposición son intensificadas en los relatos sobre la disputa por la vigencia o destrucción del tradicional estilo de vida ('terroristas que estaban detenidos y sus simpatizantes', 'presidente de la nación y su iniciativa jurídica’).

Así, tradicional estilo de vida es el segundo objeto de discurso que reconocemos delimitados en los enunciados. Los enunciadores dramatizan actores autorizados a evocar las normas del estilo de vida amenazado y a incluirse en el colectivo nacional. Los sujetos que componen este colectivo de identificación construido en los enunciados de Videla y Meli compartían con los enunciadores el saber sobre esas normas en un pasado de guerra y lo comparten en el presente del juicio.

\subsubsection{Tradicional estilo de vida}

Los enunciados de Videla y Meli inscriben enunciadores profesionales con competencias diferenciales en el campo discursivo judicial. El primero establece la necesidad de subordinar un objeto procesal a una tradición filial y mística para categorizar su validez/invalidez:

V: [...] lo voy a leer, tiene como título 'Manifestación ante los jueces'. Se compone de tres capítulos. El primero, es muy breve, es un introito, el que indica el alcance que tiene en definitiva la exposición. [...] Si nos fijamos bien, el terrorista no sólo instrumenta al hombre sino a Dios $[\ldots]$.

Meli, por su parte, asigna a un conjunto de enunciados formales el carácter de fuente de autoridad del objeto procesal polémico. El enunciador inscrito en su discurso reconstruye un universo referencial formal que denuncia excluido del juicio y argumenta la tensión entre su discurso y el del campo judicial mediante la referencia de un archivo de la lex scripta argentina o la tradición jurídica nacional:

M: [...] La doctrina tipificada en Núremberg no es extrapolable analógicamente para su aplicación a hechos acontecidos en la República Argentina durante la década del setenta. Como lo señala el Código Penal de la Nación, en su artículo segundo, las leyes penales no podrán aplicarse por analogía. [...] Un principio tan débil concebido como Nullum Crimen Sine Iure no satisface las exigencias del artículo 18 de la Constitución Nacional.

En el juego de la verdad judicial abierto por ambos enunciados, la tradición nacional es un objeto de discurso articulado con otro objeto que lo especifica: la amenaza extranjera de su destrucción. Esta relación entre la tradición nacional y su amenaza foránea opera sobre el relato de los hechos que dan surgimiento al objeto procesal polémico, guerra revolucionaria, y sobre la valoración de otros enunciadores del campo judicial. 
Las últimas palabras de Meli y Videla no representan, por lo tanto, una variación de la interpretación jurídica de los hechos, sino una re-delimitación del objeto mismo a interpretar. Escenifican, mediante un argumento histórico, un argumento jurídico. Y lo hacen agonísticamente, en la medida en que, en los términos de esa dramatización, unos argumentos históricos devienen jurídicos al mismo tiempo que argumentos jurídicos devienen históricos.

V: [...] el doctor Vaca Narvaja ${ }^{8}$ se apartó totalmente del objeto procesal de este juicio para desarrollar un peligroso revisionismo histórico cuyo objeto, apuntando a una visión progresista, no es casualmente afirmar los valores de nuestro tradicional estilo de vida [...].

M: Información falaz, totalmente desacreditada. Sin embargo, esta acusación, es uno de los pilares de todas las imputaciones ${ }^{9}$.

V: [...] Capacitada, la agresión terrorista, para producir aquellas acciones intimidatorias, estaba integrada mayoritariamente por personal no nacional, entrenada en Cuba, Siria, Palestina y Argelia o bien dentro del propio país pero con instructores foráneos [...].

M: [...] ante la ausencia del requisito inexorable de norma escrita previa impuesta por nuestra legislación interna [...] se soslaya y tergiversa esta exigencia, destacando en autos que la misma se halla asegurada por el conjunto de resoluciones, declaraciones e instrumentos convencionales que conforman el corpus del derecho internacional en las actuaciones que redactó el Ministerio Público Fiscal [...] o sea que el corpus de tratados y convenciones reemplaza, ¿no es cierto?, todo lo que sea legalidad en este país.

Lo foráneo a la tradición nacional, filial y mística en Videla, y jurídica en Meli, es designado como amenaza e identificado con lo criminal. El carácter nacional tanto de la lex scripta como de la tradición cristiana establece el lugar de sentido donde emerge un mismo colectivo profesional, el castrense con injerencia en la organización jurídica del Estado. Las últimas palabras de ambos acusados categorizan el rito judicial como la sede de una intersección simbólica. Allí convergen el tiempo procesal y el de el estado de guerra y, respectivamente, la amenaza al primero atribuida a los tratados internacionales y la amenaza al segundo, imputada a la agresión terrorista.

\subsubsection{Justicia política}

Los enunciados de los acusados despliegan una estrategia argumentativa común que construye dos objetos justicia política y derecho consuetudinario. El campo discursivo judicial donde aparecen es re-construido por las últimas palabras como un conjunto de argumentos históricos anacrónicos, sin homologación posible con los hechos estereotipados en las normas del sistema penal nacional.

\footnotetext{
${ }^{8}$ Hugo Vaca Narvaja, junto a Elba Martínez, son los abogados querellantes que representaron a los familiares de 13 de las 37 víctimas de los hechos por los que se acusó a los ex militares.

${ }^{9}$ El representante del Ministerio Público Fiscal había alegado, como vimos, que el acusado Meli, pese a su rango menor en relación con el de Videla, sí participaba de la toma de decisiones y las implementaba, formal y realmente.
} 
V: [...] Con una visión lamentablemente sesgada de la realidad no exenta de dudoso propósito, ocultando parte de los años tremendos de esa guerra y tergiversando a su vez la parte que se hace pública [...] mil quinientas personas detenidas bajo proceso o cumpliendo condena en relación con los delitos ya sindicados $[\ldots]^{10}$.

El enunciador inscrito en el enunciado de Videla establece las condiciones de emergencia del estado de guerra como equivalentes a las de una justicia en estado de excepción. Su relato designa la agresión terrorista como una interpelación de procedimientos jurídicos con objetivos políticos precisos. Entre éstos procedimientos y los llevados a cabo en los tribunales de Córdoba en el tiempo de la enunciación, se argumenta una relación de concordancia: 'mucho se ha dicho, con una visión lamentablemente no exenta de dudoso propósito'. En una intensificación de la estrategia, uno de los enunciadores del juicio incluidos al enunciado, el abogado querellante Hugo Vaca Narvaja, es categorizado como ajeno a los límites del objeto procesal inmotivado:

V: El Doctor Vaca Narvaja se apartó totalmente del objeto procesal de este juicio para desarrollar un peligroso revisionismo histórico cuyo objeto, apuntando a una visión progresista, no es casualmente afirmar los valores de nuestro tradicional estilo de vida.

La condición necesaria de lo justo reconocida en el estado de excepción del pasado aparece, en definitiva, opuesta a las de una justicia con una visión sesgada de la realidad y dudosos propósitos. Dos universos referenciales entran en disputa por la construcción de ámbitos de justicia disonantes. El construido en Las últimas palabras de Videla, al que dedicamos este estudio, es el referente de justicia que emerge de la auto-referencia. El acusado re-construye simbólicamente su rol procesal como un discurso profesional que exige a otros enunciadores del juicio una justificación externa (Alexy, 2011 [1978]). Pero, al mismo tiempo, también re-construye el rol procesal de aquellos otros como argumentos sin corrección jurídica ni arreglo a la tradición nacional.

La justicia del pasado interpelada por la amenaza de la agresión terrorista es categorizada en las últimas palabras del acusado como un conjunto de acciones cuya corrección jurídica estaba saldada por el reconocimiento a las exigencias de la sociedad argentina. Según el relato, por lo tanto, mientras en el pasado la garantía de justificación externa de lo justo provenía de la atención, por parte de la justicia, de las exigencias de la sociedad, en el presente, proviene de atender las exigencias de un enunciador profesional incluido a un nosotros nacional.

V: [...] fue justamente la sociedad argentina la principal protagonista de aquel acontecimiento bélico, objeto, en primer término, de la agresión que pretendía sojuzgarla por el terror y sujeto, luego, que ordenó a su brazo armado, a acudir en su legítima defensa [...] debemos admitir que en nuestro país, hubo una guerra interna, iniciada por las organizaciones terroristas contra las instituciones del propio estado argentino [...].

\footnotetext{
${ }^{10}$ El fragmento del discurso hace referencia a presos políticos que habían sido aprehendidos durante la presidencia de facto de Alejandro Agustín Lanusse (1971-1973) y que el Presidente constitucional, Héctor José Cámpora, liberó por Decreto de indulto $n^{\circ} 11 / 73$.
} 
El sujeto colectivo designado sociedad argentina, que el relato categoriza como objeto de la agresión terrorista en el pasado, es valorado como objeto de 'la desinformación y la propaganda artera' en el tiempo del rito judicial.

En el juego de verdad judicial, el enunciador reconstruye el estado de excepción del pasado como la motivación de una justicia racional celebrada por la guerra justa mientras que el rito judicial de desinformación, propaganda artera, sesgado y con dudosos propósitos del presente representa la actualización de ese motivo y la interpelación del antiguo sujeto de corrección jurídica: el sujeto de la guerra.

Éste configura el posicionamiento donde el enunciador inscrito en el discurso de Videla se reconoce. Los atributos jurídicos del sujeto de guerra $\mathrm{y}$, por lo tanto, del enunciador, son justificados por una argumentación que los considera delegados naturalmente por un contexto de excepción. En este dominio referencial, el sujeto no-válido encarnado en las autoridades del rito judicial presente, en cambio, es designado como aquel que, en un contexto de normalidad, posee competencias jurídicas arrogadas con fines políticos.

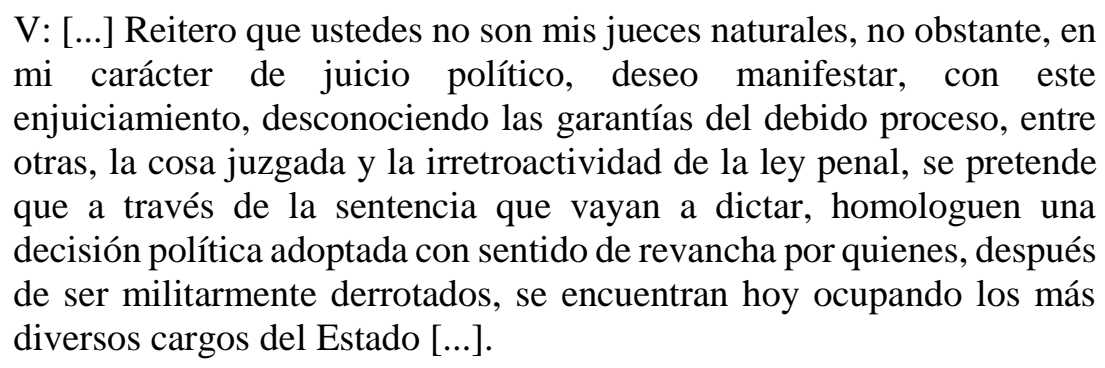

El enunciador referencia un ámbito de justicia cuya gramática prescribe que a determinados contextos predeterminados, como el producido por una amenaza foránea, corresponde por oficio jurídico el despliegue de funciones castrenses. Es decir, las relaciones establecidas entre los objetos tradición nacional amenazada y democracia de excepción activa un sistema de correspondencias que designa, para una formación profesional, la asunción de obligaciones políticas. En el orden de esta gramática, la justicia ejercida en el pasado por un sujeto de guerra no es injusta por ser política siempre que lo político se justifique en un estado de excepción. Y por lo tanto, toda justicia política que no obtenga su politicidad de una interpelación semejante no es justificable como tal.

Así, el enunciador inscrito en las últimas palabras de Videla construye dos acontecimientos que producen una intersección entre representaciones de dos tiempos, del pasado de guerra y del presente de enjuiciamiento. El primero interpeló la instrumentación de la política para el restablecimiento de un sistema jurídico y el segundo, la utilización de un sistema jurídico con objetivos políticos, como el de la revancha.

El enunciador inscrito en el enunciado de Meli delimita el objeto tradición doctrinaria argentina como el eje de distinción de dos ámbitos de justicia disonantes: el derecho consuetudinario y la lex scripta. El primero de ellos es representado como uno que reconoce el eje de distinción y lo remarca, y el segundo como el que lo desconoce y lo disuelve. 
M: El derecho de gente es una costumbre que solamente se invoca y ni siquiera se prueba, contraponiéndose a las reglas de la tipicidad penal, que es garantía de legalidad conforme a la Constitución de la Nación Argentina y al Código Procesal de la Nación [...] la totalidad de la jurisprudencia mencionada, como prueba acusatoria es posterior a los hechos investigados, por lo cual no cabe su aplicación retroactiva [...].

El enunciador dramatiza un actor procesal que comparece ante el tribunal invirtiendo la carga de la prueba. En otras palabras, escenifica una argumentación jurídica que imputa las inconsistencias jurídicas de otros enunciados del campo judicial. La estrategia discursiva consiste en referenciar un ámbito de justicia o dominio de verdad jurídica mediante una apuesta narrativa (Calvo González, 1998) donde la propia reconstrucción de la historia del derecho pone en escena una voz normalizadora del presente judicial y actualizadora del mismo plexo normativo tradicional que construye. Al igual que en el discurso de Videla, en la argumentación de Meli, los hechos designados enfrentamientos del pasado son reconstruidos como acontecimientos a los que otros enunciadores sin corrección jurídica han conferido existencia procesal.

M: [...] sin que pueda aceptarse que la gravedad o aún el carácter aberrante de los hechos que se pretende incriminar justifiquen dejar de lado el principio de irretroactividad de la ley penal [...] la convención ${ }^{11}$ no abarca los actos de tortura cometidos en la República Argentina en mil novecientos setenta y seis, diez años antes de la entrada en vigor de la convención [...] ante la ausencia del requisito inexorable de norma escrita previa impuesta por nuestra legislación interna, dictada por el congreso nacional [...] se soslaya y tergiversa esta exigencia, destacando en autos, que la misma se halla asegurada por el conjunto de resoluciones $[. .$.$] que dieron origen a las normas del ius cogens.$

En el ámbito de justicia referenciado por el discurso de Meli, no basta con reconocer y probar, en un debate judicial, un hecho de tortura, como 'los cometidos en la República Argentina', para resolver una descripción por derecho. Debe establecerse, en esta gramática, una subsunción formal de los hechos probados a la norma jurídica con obediencia al principio de legalidad. En otras palabras, la prueba válida para certificar torturas no estará dada por que sean designadas como tales por un relato judicial, sino porque lo sean por un discurso profesional que adjudique al hecho una ley previa. En las últimas palabras de Meli, el enunciado que designa 'actos de tortura cometidos en la República Argentina' no inscribe un enunciador auto-incriminado sino uno que argumenta la imposibilidad de conferirle existencia procesal a un hecho probado. Este ámbito de justicia prescribe, entonces, que lo aberrante y lo grave no designan valores nominales de hechos predeterminados o figuras jurídicas que la tradición nacional de la lex scripta admita como criterio formal de una decisión judicial. Designan, por el contrario, características que el autor de un hecho aberrante y grave puede asignar a sus prácticas sin formular, por esto, lo que Foucault (2014 [2012]) denomina la confesión que lo vincula con su ethoi. La condición de posibilidad de esta enunciación con efectos de sentido aparentemente paradójicos está dada por la restauración performativa de un régimen de saber jurídico que valida la decisión judicial justificada en subsunciones formales a la tradición nacional y excluye la justificada en las normas del ius cogens o derecho imperativo internacional sobre lo aberrante y lo grave.

\footnotetext{
${ }^{11}$ Hace referencia a la convención arribada en la reunión del Comité Internacional Contra la Tortura del 26
} de julio de 1987. 


\subsubsection{El principio legislativo de la palabra judicial y la autoridad popular}

Como señala la nueva retórica perelmaniana, los acuerdos presupuestos en el argumento jurídico traen consigo un orden de valores, jerarquías y enlaces organizados en esquemas que apelan a acuerdos tenidos con un auditorio universal.

Las últimas palabras de Videla y Meli inscriben en sus relatos un yo-enunciador que se incluye en un colectivo de identificación designado la sociedad. La sociedad es categorizada como la fuente de autoridad de las intervenciones castrenses del pasado de la guerra y los actos de enunciación del presente del juicio, y la formación profesional del yoenunciador, como la encarnación legítima de esa autoridad. Todo objeto adverso a los delimitados en la delegación pasada de la guerra y la presente de la palabra judicial deviene, por contigüidad, en adverso a lo republicano ${ }^{12}$, en la misma medida en que lo contrapuesto al enunciador, auto-referenciado como el delegado, deviene lo contrapuesto al sistema representativo.

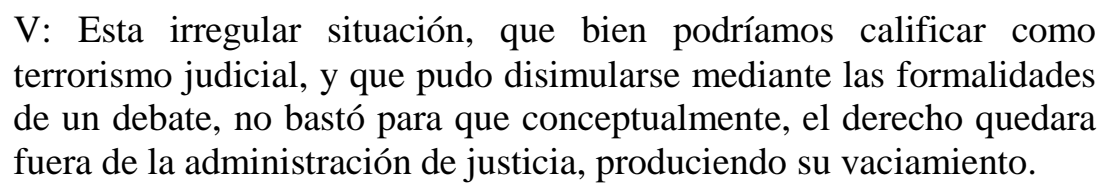

En este contexto discursivo, la categoría terrorismo judicial construye un ámbito de justicia que prescribe al rito procesal el mismo lugar de sentido que el prescrito por el relato a terrorismo subversivo. El reenvío a un referente democrático de justicia se asienta sobre un mismo eje: el carácter republicano y representativo de un enunciador que da voz al sujeto colectivo nacional que le ha delegado la palabra.

V: [...] cuando los militares argentinos lanzaron su campaña contra el
terrorismo, la sociedad y el Estado estaban al borde del colapso [...]
señor presidente, señores jueces, no he venido hoy a defenderme, ni a
alegar en mi defensa, defensa que a mi juicio no guarda sentido. Frente
a esa realidad que no está en mis manos modificar, asumiré bajo
protesta, la injusta condena que se me pueda imponer, como
contribución, de mi parte, al logro de la concordia nacional [...].

La apuesta narrativa de Videla reconstruye el pasado relatado por otros enunciadores del campo judicial como uno intermedio entre una interpelación terrorista y una respuesta republicana, como uno donde la tensión estratégica entre el discurso profesional castrense invierte el profesional jurídico, en un contexto de democracia de excepción que interpela las competencias jurídicas de los mandos militares. Es en relación con la consagración de la respuesta republicana al carácter de hecho justiciable que un enunciador con juicio proprio categoriza el contrasentido de tomar a cargo defenderme, alegar mi defensa. De esta manera,

\footnotetext{
${ }^{12} \mathrm{Si}$ el juego de la verdad jurídica de un rito judicial consiste en solicitar el reconocimiento del principio legislativo del discurso jurídico, de la función reglamentaria de los operadores jurídicos, el de los acusados puede invertirlo. El discurso de un acusado de crímenes de Estado, en otras palabras, puede reivindicar agonísticamente el principio, referenciando otro conjunto de leyes y relatando otros actos legislativos. En contestación a la autoridad que interpela su palabra, el acusado se reserva la posibilidad del antagonismo de no-reconocerse en la ley que lo juzga, como lo propone la ficción que Foucault (2014 [2012]) atribuye a la práctica jurídica. Se reserva como un punto de resistencia que desanda la verdad el ethoi construido para él en el discurso de la acusación. Se reserva, en términos bajtineanos, el poder de inversión de un nuevo sentido a su posicionamiento ritual que lo represente como enunciado conclusivo.
} 
la pregunta formulada por Videla, ‘qquién, a ciencia cierta, puede decir cuándo comenzó esta guerra?', es contestada tanto el enunciador inscrito en sus últimas palabras como el del enunciado de Meli. La voz que aparece cuando ambos toman la palabra reenvía a un topoï, en el sentido aludido por Marc Angenot (2010), que podemos transcribir en el siguiente postulado: el comienzo de una guerra sólo puede ser documentado por un enunciador perteneciente a una formación profesional castrense-jurídica, que se corresponde a la formación interpelada en el pasado a comenzar la guerra.

M: [...] adhiero totalmente a lo expresado por el Teniente General Jorge Rafael Videla. Menciono su grado y cargo, porque para mí, educado en el ejército, continuará siendo mi comandante en jefe. Estoy siendo juzgado por la presunta comisión de delitos de lesa humanidad con carácter imprescriptible por la única razón de haber ejercido el cargo de jefe de estado mayor de la cuarta brigada de infantería aerotransportada durante el segundo semestre del año mil novecientos setenta y seis. Sin responsabilidad simultánea por el comando del área de defensa trescientos once que como está acreditado en autos, fue una unidad organizada en forma independiente para llevar a cabo exclusivamente, la lucha contra la subversión [...].

M: [...] El carácter manifiestamente político y unilateral de la persecución, no facilita la superación de antinomias en pos de una convivencia pacífica y organizada en vistas a la paz y el progreso de nuestra patria $[\ldots]$.

El objeto delimitado en designaciones como terrorismo judicial y subversión se articula, en el relato de Meli, con otro: democracia de excepción. El argumento históricojurídico consiste en afirmar que mientras, en el pasado, un contexto análogo había motivado, naturalmente, el despliegue de las competencias profesionales, en el presente, justifica su reposición.

En este marco, el yo-enunciador inscrito en las últimas palabras del acusado argumenta que el hecho justiciable no está constituido por los hechos que se le imputan, sino por las antinomias reforzadas por el discurso de la imputación.

\subsubsection{Clandestinidad}

En el dominio donde se delimitan y emergen los objetos discursivos democracia de excepción y agresión interpelante, emergen y se articulan singularmente con ellos los referentes clandestinidad estructural y orgánica. La formación profesional con la que se identifican los enunciadores es categorizada como una contrapuesta a una formación ad hoc, irregular, denominada organizaciones terroristas.

V: [...] El ejército revolucionario del pueblo, encabezado por Santucho [...] la guerrilla urbana, en cuyo marco, un joven cumplía durante un día su cometido natural como hijo, como estudiante y obrero, y durante la noche, asaltaba, secuestraba y colocaba bombas [...] librada contra un enemigo mimético, que no exhibía uniforme ni bandera, se llegó a situaciones límites que ensombrecieron al país, con actos rayanos en el horror $[\ldots]$. 
Lo clandestino representa una categoría atribuida al sujeto de la amenaza a la tradición nacional, que imita (desde la clandestinidad) lo amenazado, con el fin último de suprimirlo. El ámbito de justicia al que ambos enunciadores reenvían define esta categoría como el rasgo distintivo de un actor que el relato del campo discursivo judicial no ha reconocido. Los enunciadores del rito judiciales, así, son categorizados como excluidos del régimen aceptable de prácticas jurídicas designado en la fórmula la tradición argentina (filial y mística en Videla y jurídica en Meli).

Con esto, en el curso de las argumentaciones, el objeto democracia de excepción se ve sobre-determinado en otro: justicia de excepción. La invalidez jurídica del procedimiento no es asignada por enunciadores que imputan vicios procedimentales, sino por unos que construyen un orden referente de juridicidad válida en relación de correspondencia con los objetos tradición nacional y estilo de vida, y se identifican con el sujeto colectivo que los posee (nuestra tradición y nuestro estilo).

\section{La dramatización del argumento jurídico}

Las últimas palabras de Videla inscriben un enunciador que conserva competencias profesionales castrenses y las exhibe como fuente de autoridad política y jurídica. Autorizado, el sujeto de enunciación vuelve el orden que lo autorizó en régimen ritual de su práctica. Si bien, el sujeto hablante toma la palabra a instancias de su otorgamiento por los jueces del tribunal, el enunciador inscrito en el enunciado escenifica el rol procesal de administrador del juego lingüístico y polémico, en términos foucaultianos:

$\mathrm{V}:[\ldots]$ Aprovecho para agradecer a mis camaradas que han cedido parte
de su tiempo para que yo lo pueda incorporar al déficit del mío [...] Mi
conducta ha sido llamarme, en general a un prudente silencio. Lo que
no quita que en esta oportunidad, omita... exprese como... he... una
reflexión en la que no voy a polemizar $[\ldots . .$.

Los enunciadores se auto-referencian como sujetos identificados con uno profesional, de respuestas de oficios en contextos de excepción. Éste, inscrito en el colectivo castrense-jurídico, conserva, en el presente de los relatos, las competencias jurídicas transferidas a ellos en el pasado relatado.

En síntesis, las últimas palabras de Meli inscriben un enunciador autorizado por la tradición jurídica nacional de la lex scripta. Uno que construye una posición de sujeto con acceso al archivo de la doctrina y que transmuta relatos en argumentos jurídicos y últimas palabras en alegatos. El enunciador inscrito en la formación castrense-jurídica interpelada construye una posición de saber que corre una doble suerte a la luz de las tensiones estratégicas del campo judicial. Por un lado, esa posición se auto-designa como autorizada a producir efectos con fuerza simbólica en las relaciones de fuerza que construyen el ámbito de justicia válido y a reclamar, por lo tanto, la auctoritas de enunciación por la sociedad argentina.

Sin embargo, el análisis no puede sustraerse al régimen de prácticas y efectos de derecho del campo discursivo donde estos enunciadores emergen interdelimitados con otros sujetos de enunciado en el plano de las relaciones de fuerza simbólica de un juicio. Debe 
reconocer que los acusados, a quienes el juez solicita la dramatización de las últimas palabras (Foucault, 2014 [2012]), no constituyen un punto de resistencia posible en la relación de fuerza que la práctica jurídica orienta a la producción de efectos jurídico-penales. Ambos órdenes de efectos, el de los simbólicos de las últimas palabras de acusados y el de los formales del discurso de escamoteo burocrático de la pena, componen un campo semántico jurídico con movimientos contradictorios y discontinuidades.

El discurso de Meli reconstruye el campo discursivo judicial como la sede de una controversia entre una posición profesional normativa y una jurisprudencial apoyada en el derecho imperativo internacional, o ius cogens. El de Videla reconoce un campo adversativo donde dos posicionamientos zanjan sus disputas. Uno de ellos es representado como el que reemplaza preámbulos o exposiciones de motivos por introitos religiosos y categoriza las guerras justas y los juicios justos como tributos a la tradición nacional filial y católica apostólica romana y el otro como su contrapunto.

En ambos casos, la controversia es categorizada como injusta en la medida en que el segundo posicionamiento desplaza, luego de degradarlo, al primero. El campo judicial es valorado tanto por Videla como por Meli como superficie de emergencia de prácticas jurídicas no-nacionales que someten la normatividad local a los designios de una foránea, difundida, como vimos, por la 'desinformación y la propaganda artera'.

\section{Conclusión}

En síntesis, es posible reconocer cómo un conjunto de referentes u objetos de discurso (estado de guerra, amenaza, democracia de excepción, autoridad profesional, clandestinidad y autoridad popular) se subsumen a un universo referencial que remite, en conjunto, a un ámbito de justicia que establece la tradición nacional como un ideal regulador del argumento jurídico. Los objetos delimitados las últimas palabras tanto de Videla como de Meli construyen su posicionamiento y categorizan los demás enunciadores del campo judicial en función del efecto de sentido de ese universo referencial.

Los acusados inscriben enunciadores que re-categorizan otros actores procesales como enemigos no-nacionales e invierten el orden de la tensión estratégica comúnmente reconocida en el ámbito formal entre enunciadores legos y enunciadores profesionales. Así, se da vista simbólica a un objeto procesal alternativo, polémico, que puede ser enunciado como sigue: las acciones premeditadas atribuibles a sujetos individualizables precipitaron acciones normalizadoras a cargo de sujetos colectivos: el Estado argentino, la sociedad, las Fuerzas Armadas etc.

La continuidad de estudios en esta dirección permitiría dar mejores respuestas a una pregunta que resuena con especial intensidad durante el desarrollo de estos juicios en la región latinoamericana: ¿qué objetos son delimitados y re-delimitados en discursos que se auto-referencian su relato como un argumento jurídico que re-construye pasados trágicos recientes y polemiza con otros relatos? 


\section{Referencias}

ALEXY, Robert [1978]. A theory of legal argumentation. The theory of rational discourse as theory of legal justification. Oxford, NY: OUP, 2011.

BARTHES, Roland [1968]. El efecto de realidad. REVISTA DE OCCIDENTE, n. 386387, 210-219, 2013. Disponible en http://semioticagesc.com/wpcontent/uploads/2015/10/El-efecto-de-realidad.pdf.

CÁRCOVA, Carlos. Notas acerca de la teoría crítica del derecho. En: COURTIS, Ch. (comp.). Desde otra mirada. Textos de Teoría Crítica del Derecho. Buenos Aires: EUDEBA, 2009. p. 19-38.

DERRIDA, Jacques. Fuerza de ley: 'el fundamento místico de la autoridad'. DOXA [Cuadernos de filosofía del derecho], n. 11, 129-191, 1992. Disponible en http://www.biblioteca.org.ar/libros/141832.pdf. Acceso en abril de 2017.

CIULLA e SILVA, Alena. Processos de referência e suas funções discursivas - o universo literário dos contos. Tese. Doutorado em Linguística, Centro de Humanidades da Universidade Federal do Ceará, Fortaleza, 2008. Disponible en http://www.repositorio.ufc.br/bitstream/riufc/3615/1/2008 tese_ACSilva.pdf. Acceso en abril de 2017.

FEIERSTEIN, D. Juicios. Sobre la elaboración del genocidio II. Buenos Aires: Fondo de Cultura Económica, 2015.

FOUCAULT, Michel [2012]. Obrar mal, decir la verdad. La función de la confesión en la justicia. Buenos Aires: Siglo XXI, 2014.

[1969]. La arqueología del saber. Buenos Aires: Siglo XXI, 2011.

[1971]. El orden del discurso. Barcelona: Tusquets, 2008.

GARCÍA ROMANUTTI, Hernán. Judith Butler lectora de Michel Foucault. Consideraciones sobre la performatividad como origen y efecto de la normatividad. Segundas Jornadas de Estudios de la Performance, 9 Y 10 de octubre de 2014. Universidad Nacional de Córdoba, 2014.

HEFFER, Chris. The Language of Jury Trial. A corpus-aided analysis of legal-lay discourse. NY: Palgrave MacMillan, 2005.

KENNEDY, Duncan. Izquierda y derecho. Ensayos de teoría jurídica crítica. Buenos Aires: Siglo XXI, 2010.

LANDOWSKI, Eric [1986]. Una aproximación semiótica y narrativa al derecho. Cuadernos del Instituto de Investigaciones Jurídicas, [Sobre el derecho como discurso], Universidad Nacional Autónoma de México, n. 14, 327-356, 1990. Disponible en http://biblio.juridicas.unam.mx/libros/4/1743/9.pdf. Acceso en abril de 2017. 
LORENZETTI, R.; KRAUT, A. Derechos humanos: justicia y reparación. La experiencia de los juicios en la Argentina. Crímenes de lesa humanidad. Buenos Aires: Sudamericana, 2011 .

MARÍ, Enrique [1980]. "Moi, Pierre Riviere...” y el mito de la uniformidad semántica en las ciencias jurídicas y sociales. En: LEGENDRE, P. et al. El discurso jurídico. Perspectiva psicoanalítica y otros abordajes epistemológicos. Buenos Aires: Hachette, 1982. p. 53-83.

MONDADA, L.; DUBOIS, D. [1995]. Construção dos objetos de discurso e categorização: Uma abordagem dos processos de referenciação. Em: CAVALCANTE, M.M. et al. (Orgs.). Referenciação. São Paulo: Contexto, 2003. p. 17-52.

RUIZ, A. Derecho, democracia y teorías criticas al fin de siglo. En: COURTIS, Ch. (comp.). Desde otra mirada. Textos de Teoría Crítica del Derecho. Buenos Aires: EUDEBA, 2009. p. 9-18.

SIKKINK, Kathryn. La cascada de justicia. Cómo lo juicios de lesa humanidad están cambiando el mundo de la política. Barcelona: Gedisa, 2013.

Artigo recebido em: abril de 2017.

Aprovado e revisado em: setembro de 2017.

Publicado em: novembro de 2017.

\section{Para citar este texto:}

ANICETO, Paulo Damián. Las últimas palabras de Videla y Meli en tribunales argentinos. Emergencias y articulación de objetos de discurso. Entremeios [Revista de Estudos do Discurso, on-line, www.entremeios.inf.br], Seção Estudos, Programa de PósGraduação em Ciências da Linguagem (PPGCL), Universidade do Vale do Sapucaí (UNIVÁS), Pouso Alegre (MG), vol. 15, p. 75-91, jul. - dez. 2017.

DOI: http://dx.doi.org/10.20337/ISSN2179-3514revistaENTREMEIOSvol15pagina75a91 